\title{
Resistance of Stem-Like Cells From Neuroblastoma Cell Lines to Commonly Used Chemotherapeutic Agents
}

\author{
Sharada D. Vangipuram, PhD, ${ }^{*}$ Zhihong J. Wang, MD, PhD, and William D. Lyman, PhD
}

\begin{abstract}
Background. Cancer stem cell theory suggests that the presence of tumor initiating stem-like cells in cancers may be responsible for cancer progression and relapse. CD133 cell surface maker expression has been used to identify stem-like cells in cancer cell lines. Our goal was to identify such cells in neuroblastoma cell lines and to study the cytotoxicity of common anticancer drugs for those cells. Materials and Methods. CD133+ cells from SK-N-SH and SK-N-BE cell lines were isolated using magnetic microbeads. Cytotoxicity of four anticancer drugs was studied on CD133+ and CD133populations. The percentage of live, apoptotic, and dead cells in each population after drug treatment was estimated by MTT and PI/ Annexin-binding assays. Western blot analyses were used to identify differences in the expression of kinases. Results. Eight to 10\% of SK$\mathrm{N}-\mathrm{SH}$ and $3-5 \%$ of SK-N-BE cells were CD133+. These cells were
\end{abstract}

more resistant than CD133- cells to all four chemotherapeutic agents tested in the MTT assay. Decreased apoptosis was observed in CD133 + cells compared to CD133 - cells by Pl/Annexin V-binding assay. Western blot analysis showed that CD133+ cells expressed less MKP-1. Phosphorylated forms of both ERK and P-38 kinases were expressed at higher levels in CD133+ cells than in CD133cells. Conclusions. This study suggests that CD133+ cells are more resistant to anticancer drugs than CD133- cells. Differences in the expression and phosphorylation of kinases could be partially responsible for this difference. Targeting CD133-expressing cells could be a strategy to develop more effective treatments for neuroblastoma. Pediatr Blood Cancer 2010;54:361-368.

(c) 2009 Wiley-Liss, Inc.

Key words: cancer stem cells; drug resistance; neuroblastoma

\section{INTRODUCTION}

The cancer stem cell theory states that tumors contain a subset of cells that are capable of self-renewal and differentiation, can propagate tumor growth, and are resistant to apoptosis [1]. Recent evidence shows that cancer tissue contains a hierarchical organization of cells including stem cells similar to normal tissue. These stem-like cancer cells are similar to normal stem cells [2,3] and can be responsible for cancer progression and metastasis. Normal stem cells can be transformed into cancer stem cells after genetic modifications such as mutations in oncogenes, tumor suppressor genes, and repair genes or due to epigenetic alterations such as histone modification and abnormal methylation [4]. Recently, several cancers including those of the blood [5,6], breast [7], brain [8], and colon [9] were shown to have stem-like cells. Presence of these stem-like cells in solid tumors was first reported in human breast tumor samples [7].

Subsequently, several other human solid tumors have been studied for the presence of tumor initiating stem-like cells.

CD133 has been shown to be a marker of cancer stem cells. It is a five transmembrane domain glycoprotein expressed by untransformed hematopoietic and neural progenitors $[8,10]$. It has been reported that cancer cells expressing stem cell markers are chemoresistant and could thus be responsible for clinical relapse [11]. Mahller et al. [12] have reported the presence of pluripotent tumor initiating cells in neuroblastoma cell lines that are CD133 and nestin positive and are susceptible to a targeted oncolytic virus. Glioblastoma-derived CD133+ and CD133 - cells have been shown to have differential growth characteristics and molecular profiles [13]. Singh et al. [8] have shown that human brain tumors contain CD133+ stem-like cells that are capable of growing tumors in immunodeficient mice. Nineteen to $29 \%$ of cells in glioblastomas and $6-21 \%$ of cells of medulloblastomas are reported to be $\mathrm{CD} 133+$ and tumorigenic [3].

Neuroblastoma is the most common extra-cranial solid tumor of childhood. It causes, approximately, $15 \%$ of deaths attributable to malignant conditions in children [14]. Despite multimodal treatment, the outcome of high-risk neuroblastoma is still dismal with a

(C) 2009 Wiley-Liss, Inc.

EFS $<50 \%$ [12]. One of the major causes of poor outcome is drug resistance which leads to treatment failure. Based on the above reports, we hypothesize that $\mathrm{CD} 133+$ cells isolated from neuroblastoma cancer cell lines are more resistant to commonly used chemotherapeutic agents namely cisplatin, etopside, doxorubicin, and carboplatin than CD133- cells. In this study, CD133expressing stem-like cells were positively isolated from the neuroblastoma cell lines SK-N-SH and SK-N-BE, and the effect of commonly used chemotherapeutic agents was studied on CD133+ and CD133 - populations. Here we report that CD133+ cancer cells are more resistant to chemotherapeutic agents than CD133- cells

\section{MATERIALS AND METHODS}

\section{Cell Lines}

Human neuroblastoma cell lines SK-N-BE and SK-N-SH were obtained from American Type Culture Collection, Rockville, MD and SH-SY-5Y, osteosarcoma cell lines U2OS and P16T, and Ewing sarcoma cell line EWS-1 were obtained from the Children's Hospital of Michigan Cell Culture Laboratory frozen-stored cell bank. After thawing, the cells were cultured in RPMI medium (RPMI; Fisher Scientific, Pittsburg, PA) supplemented with $10 \%$ FBS (Invitrogen, Carlsbad, CA) and 1\% antibiotic/antimycotic

Additional supporting information may be found in the online version of this article.

The Carman and Ann Adams Department of Pediatrics, Children's Research Center of Michigan, Wayne State University School of Medicine, Children's Hospital of Michigan, Detroit, Michigan

Conflict of interest: Nothing to report.

*Correspondence to: Sharada D. Vangipuram, Children's Hospital of Michigan, 3901 Beaubien Street, 3N73, Detroit, MI 48201.

E-mail: svangipuram@med.wayne.edu

Received 16 July 2009; Accepted 1 October 2009 
solution, in a humidified atmosphere containing $5 \% \mathrm{CO}_{2}$ at $37^{\circ} \mathrm{C}$. Cells were trypsinized and passaged at a ratio of 1:3 at confluence or washed in culture medium and counted for experiments.

\section{Immunophenotyping by FACS Analysis}

Trypsinized cells were washed in ice-cold PBS and stained for CD133 expression as previously explained by Barami et al. [15]. Briefly, the cells were resuspended in PBS $+30 \%$ adult bovine serum at a concentration of $5 \times 10^{6}$ cells $/ \mathrm{ml}$ and added to twelve $75 \mathrm{~mm}$ tubes at $100 \mu \mathrm{l} /$ tube containing pre-aliquoted monoclonal antibodies CD133 PE and CD45 FITC. After incubating cells with antibody in the dark for $30 \mathrm{~min}$ at room temperature, the cells were washed with $1 \mathrm{ml}$ of cold PBS and resuspended in $0.5 \mathrm{ml}$ of PBS + Fix (PBS $+2.5 \%$ Coulter Fixative). A two-color analysis was performed using a Coulter XL Flow Cytometer (Coulter Corp., Miami, FL) gated on the viable cell population as inferred from forward and side scatter (FS and SS) analyses. Cells were incubated with isotype-matched controls for all samples.

\section{Isolation of CD133+ Cell Population}

Confluent layers of SK-N-SH or SK-N-BE cells were trypsinized and washed with PBS. CD133+ cells were positively selected from the cell suspension using MACS cell isolation kit (Miltenyi Biotechnologies, Auburn, CA). Briefly, the cells were resuspended in PBS containing $0.5 \%$ bovine serum albumin and $2 \mathrm{mmol} / \mathrm{L}$ EDTA and incubated with CD133/1 antibody labeled magnetic microbeads for $30 \mathrm{~min}$ at $4^{\circ} \mathrm{C}$. Subsequently, CD133+ cells were isolated by magnetic cell separating columns. The purity of the isolated cell population was estimated by flow cytometry using anti-CD133 or isotype control antibody (Miltenyi Biotechnologies).

Equal numbers of EWS-1 cells with high percentage of CD133+ cells were incubated either with anti-CD133 antibody-labeled magnetic microbeads or with media for $30 \mathrm{~min}$ at $4{ }^{\circ} \mathrm{C}$ to serve as positive control. Subsequently, the cells were washed and treated with various doses of chemotherapeutic agents and percentage live cells estimated by MTT assay as described below.

\section{Treatment With Chemotherapeutic Agents}

CD133+ and CD133 - cells from cell lines were seeded in 96well tissue culture plates at a density of $10 \times 10^{3}$ cells/well and incubated for $24 \mathrm{hr}$ before the addition of various drugs. The cells were incubated with various doses of Cisplatin $(0-50 \mu \mathrm{g} / \mathrm{ml}$; SICOR Pharmaceuticals, Irvine, CA), etopside $(0-200 \mu \mathrm{g} / \mathrm{ml})$, and doxorubicin $(0-200 \mathrm{ng} / \mathrm{ml}$; Bedford Laboratories, Bedford, $\mathrm{OH})$, and carboplatin (0-200 $\mu \mathrm{M}$; SICOR Pharmaceuticals, CA), for 24,48 , or $72 \mathrm{hr}$. At the end of the incubation period the cell survival was directly estimated by MTT assay or the cells were trypsinized and used for Annexin V/PI analysis or lysed for Western blot analysis.

\section{MTT Assays}

MTT assays were performed as previously described [16]. Briefly, at the end of the incubation period with cisplatin, etopside, carboplatin, or doxorubicin, the cells were incubated with MTT solution, and subsequently acid isopropanol was added to dissolve formazan crystals. Absorbance was measured using a $\mathrm{V}_{\max }$ microplate reader (Molecular Devices, Sunnyvale, CA) at $590 \mathrm{~nm}$, and percentage of cell survival was calculated.

\section{Detection of Apoptosis Using Annexin V/PI Staining}

The protocol described by Ozgen et al. [17] was modified and used for the detection of apoptosis. Cells from control (with no drug added) and experimental 96-well plates were trypsinized and resuspended at a concentration of 1 or $2 \times 10^{6}$ cells $/ \mathrm{ml}$ in RPMI + $10 \%$ FBS. Apoptosis was estimated using the Apoptosis Detection Kit (R\&D Systems, Minneapolis, MN). Briefly, $50 \mu 1$ of cell suspensions was stained by adding $10 \mu \mathrm{l}$ of diluted Annexin VFITC (AnxV) and $10 \mu \mathrm{l}$ of $250 \mu \mathrm{g} / \mathrm{ml}$ of propidium iodide (PI). After 15 min of incubation in the dark, the reaction was diluted with $0.4 \mathrm{ml}$ of binding buffer and then analyzed using a Coulter XL Flow Cytometer (Coulter Corp.). Cells were gated to include the viable cell populations based on FS and SS character, and these gated events were analyzed on two-color histograms to identify AnnexinV-expressing cells. Drug sensitivity and treatment variables were assessed by the addition of Flow Count Fluorospheres (Coulter Corp.) to the final $0.4 \mathrm{ml}$ of added binding buffer. The reactions were performed with drug-treated and control cells that had been initially cultured at identical cell densities and then harvested and resuspended in equivalent volumes. Absolute, relative viable, dead, and apoptotic counts were determined by tracking the Flow Count beads in the FL2 channel.

\section{Polyacrylamide Gel Electrophoresis (PAGE) and Western Blotting}

Whole-cell lysates were prepared as described [16]. Cell lysates $(30-100 \mu \mathrm{g})$ were electrophoresed through 4-10\% SDS-PAGE. The separated proteins on gels were transferred to PVD membranes (Schleicher \& Schuell, Inc., Keene, NH) using Bio-Rad mini gel electrotransfer system. Non-specific binding was blocked with blocking buffer containing $10 \%$ fat-free milk powder in phosphatebuffered saline (PBS) for $1 \mathrm{hr}$ at room temperature, followed by incubation with primary antibodies in blocking buffer with $5 \%$ fatfree milk powder overnight at $4{ }^{\circ} \mathrm{C}$ and room temperature for $1 \mathrm{hr}$. The membrane was then washed three times with PBS, and incubated with secondary antibody for $1 \mathrm{hr}$ at room temperature and washed three times. The bound antibody was detected using Chemiluminescence reagent (Amersham Pharmacia Biotech, Piscataway, NJ) according to the manufacturer's protocol.

\section{Statistical Analysis}

Data are expressed as mean \pm SD. The mean percentages of live or dead cells between groups were compared using parametric independent samples $t$-test. Appropriate assumptions (normality and/or homogeneity of variances) were checked and verified. Statistically significant differences were considered achieved with a $P$-value $<0.05$.

\section{RESULTS}

Approximately, $85 \%$ of cells in the Ewings sarcoma cell line EWS-1 were CD133 + (Fig. 1A) while neuroblastoma cell lines SK- 


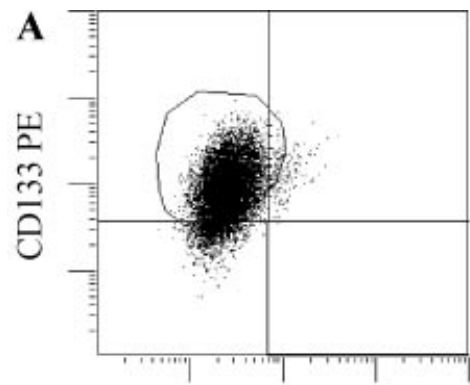

CD45 FITC

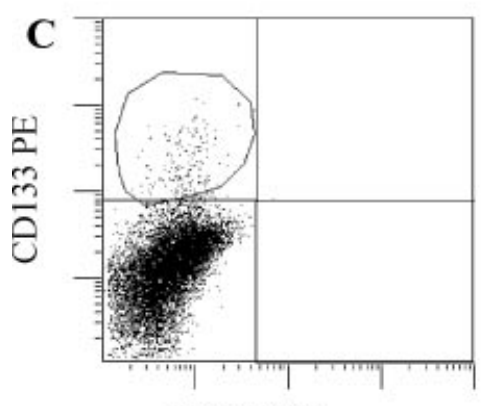

CD45 FITC

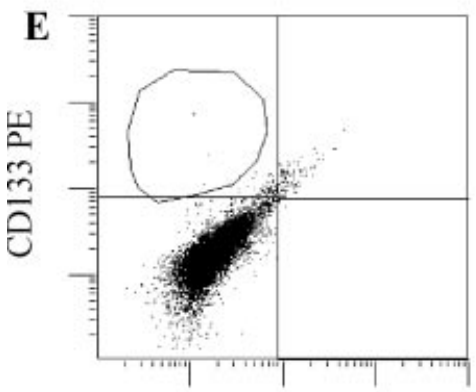

CD45 FITC

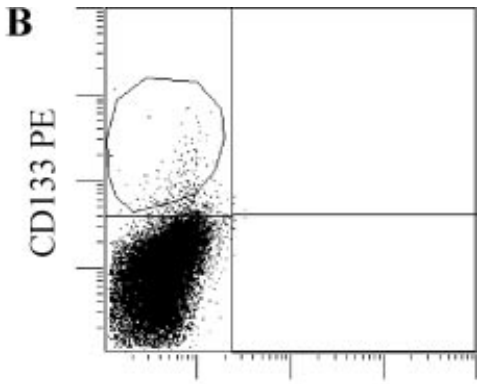

CD45 FITC

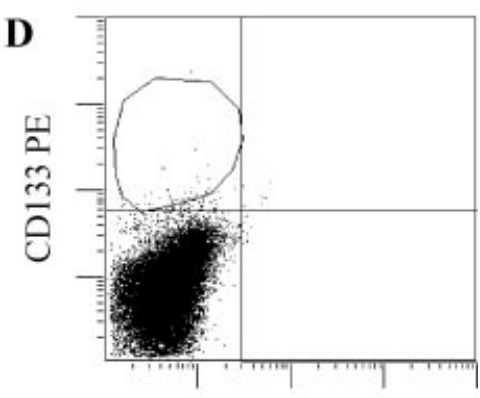

CD45 FITC

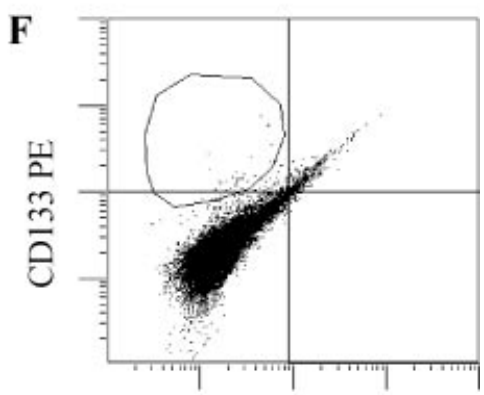

CD45 FITC

Fig. 1. Percentage of CD133 expressing cells in cell lines: (A) EWS-1: 85\%; (B) SK-N-SH: 8-10\%; (C) SK-N-BE: 3-5\%; (D) SH-SY-5Y: $<0.5 \%$; (E) U20S: 0.5\%; and (F) P16T: $<0.5 \%$.

N-SH and SK-N-BE contained $8-10 \%$ and $3-5 \%$ CD133+ cells, respectively (Fig. 1B,C). Neuroblastoma cell line SH-SY-5Y and osteosarcoma lines U20S and P16T had less than 0.5\% CD133+ cells (Fig. 1D-F).

CD133-expressing cells were positively isolated from cell line SK-N-SH using magnetic microbeads and the purity of the population was subsequently confirmed by immunophenotyping. Greater than $85 \%$ of the isolated cells expressed CD133.

CD133+ and CD133 - cells from the cell line SK-N-SH treated with various concentrations of chemotherapeutic drugs resulted in a dose-related reduction in the percentage of live cells as estimated by MTT assay at 24, 48, and $72 \mathrm{hr}$ (Fig. 2A-D). Further in all cases, CD133+ population had a significantly higher percentage of live cells compared to CD133- population. At $24 \mathrm{hr}$ of treatment, although there was a higher percentage of live cells in CD133+ population, statistically significant difference was not observed between the CD133 + and CD133 - groups with cisplatin, etopside, doxorubicin, and carboplatin treatment as estimated by the MTT assay. However, after $48 \mathrm{hr}$ of treatment with cisplatin at concen- trations $6.25-50 \mu \mathrm{g} / \mathrm{ml}, \mathrm{CD} 133+$ population had a significantly higher percentage of live cells than CD133- population. Similarly, at etopside concentrations of $12.5-200 \mu \mathrm{g} / \mathrm{ml}$ and doxorubicin at $100-200 \mu \mathrm{g} / \mathrm{ml} \mathrm{CD} 133+$ cells had significantly greater percentages of live cells. At $72 \mathrm{hr}$, at all doses tested of cisplatin $(3.125-50 \mu \mathrm{g} /$ $\mathrm{ml}$ ) etopside $(3.125-200 \mu \mathrm{g} / \mathrm{ml})$, doxorubicin $(3.125-200 \mathrm{ng} / \mathrm{ml})$, and carboplatin $(12.5-200 \mu \mathrm{M} / \mathrm{ml})$, a significantly higher percentage of live cells were estimated in CD133+ populations (Fig. 2).

Estimation of the percentage dead or apoptotic cells in both groups treated with low and high doses of drugs using Annexin V/PI detection kit showed that CD133+ had a significantly lower percentage of dead cells relative to control compared to the CD133group consistent with the result obtained by the MTT assay (Fig. 3). These results suggest that CD133+ cells are more resistant to druginduced apoptosis compared to CD133- cells.

CD133 + and CD133 - cells from the cell line SK-N-BE treated with various concentrations of cisplatin resulted in a dose-related reduction in the percentage of live cells as estimated by MTT assay at $24 \mathrm{hr}$. Further in all cases, CD133+ population had a significantly 
A

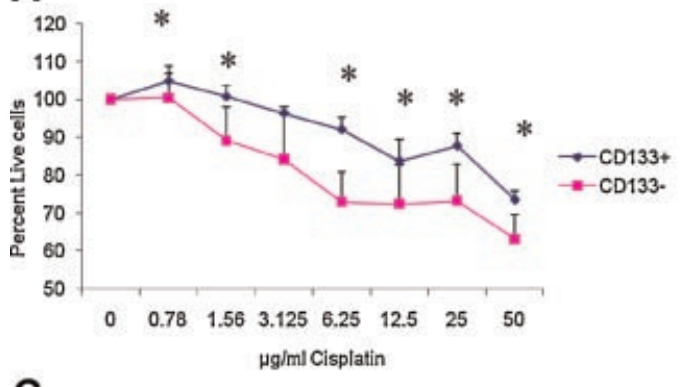

C

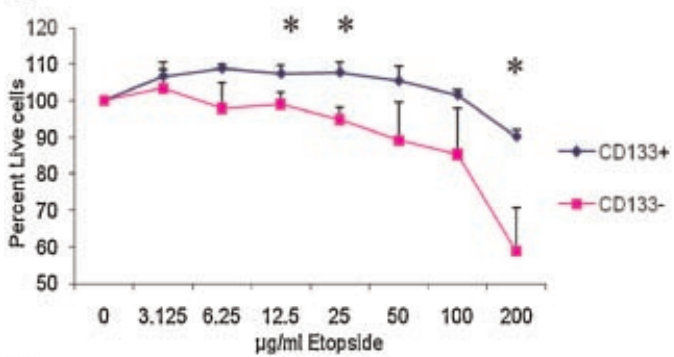

E

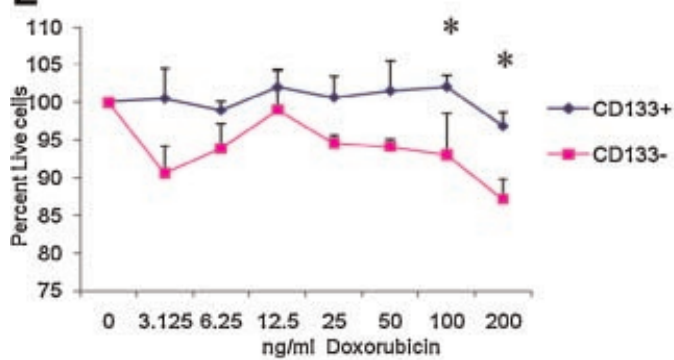

B

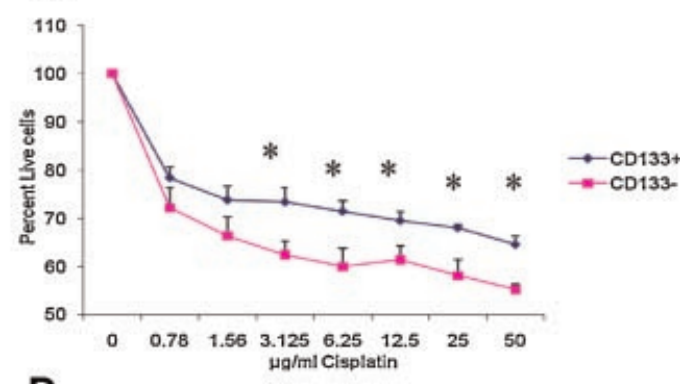

D

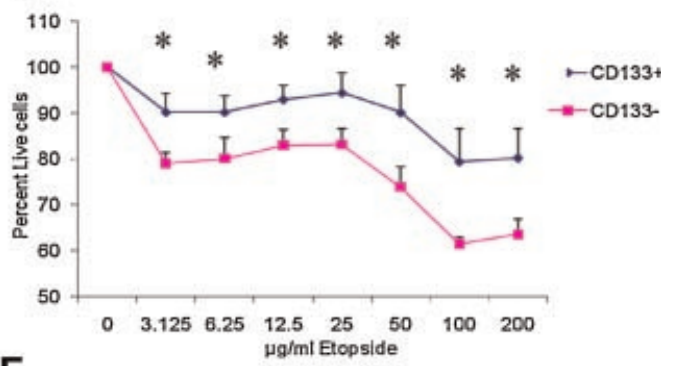

$\mathbf{F}_{110}$

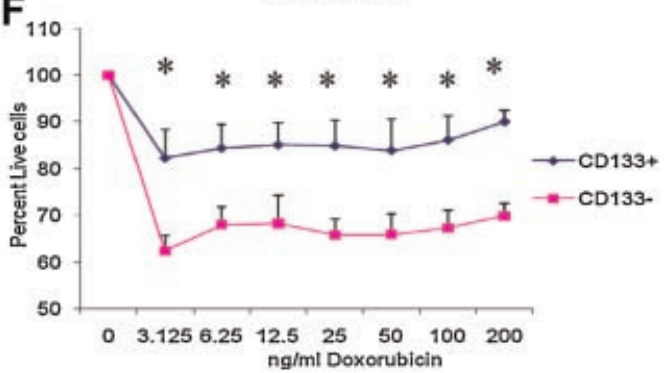

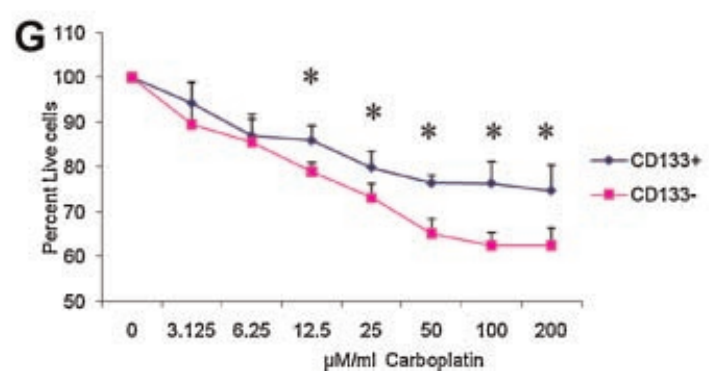

Fig. 2. Percentage of live cells in CD133+ and CD133- populations of cell line SK-N-SH after exposure to chemotherapeutic agents. A: Cisplatin-48 hr; (B) cisplatin-72 hr; (C) etopside-48 hr; (D) etopside-72 hr; (E) doxorubicin-48 hr; (F) doxorubicin-72 hr; (G) carboplatin $-72 \mathrm{hr}$. Values are expressed as a percentage of untreated controls and are mean $\pm \mathrm{SD}(\mathrm{n}=6$; $* P<0.05)$. [Color figure can be viewed in the online issue, which is available at www.interscience.wiley.com.]

higher percentage of live cells compared to CD133- population (Fig. 4).

EWS- 1 cell line with $>85 \%$ CD133 + cells was used as a control to estimate the possible role of the microbeads used to isolate the CD133+ cells in the observed resistance. The presence of microbeads caused no difference in cell viability compared to cells without beads at all doses tested with cisplatin, etopside, doxorubicin, and carboplatin (data shown as Supplemental Information Online, Fig. 6).

Western blot analysis was performed to study the levels of phosphorylated and total forms of select MAP kinases involved in apoptotic and cell survival mechanisms (Fig. 5). CD133+ cells constitutively expressed lower levels of MKP-1 compared to
CD133 - population. Phosphorylated P-38 and P-ERK were expressed at significantly higher levels in CD133+ cells while there was no difference in the expression of phosphorylated form of P-JNK and the expression of total P-38, ERK, or JNK kinases between $\mathrm{CD} 133+$ and negative groups.

\section{DISCUSSION}

According to the cancer stem cell theory, cancers develop from a small number of stem-like cells that are capable of self-renewal as well as differentiation. These cells are resistant to conventional drug therapies and have a high drug efflux capacity [11,18,19]. Cancer stem cells have been identified in acute myeloid leukemia [5] 


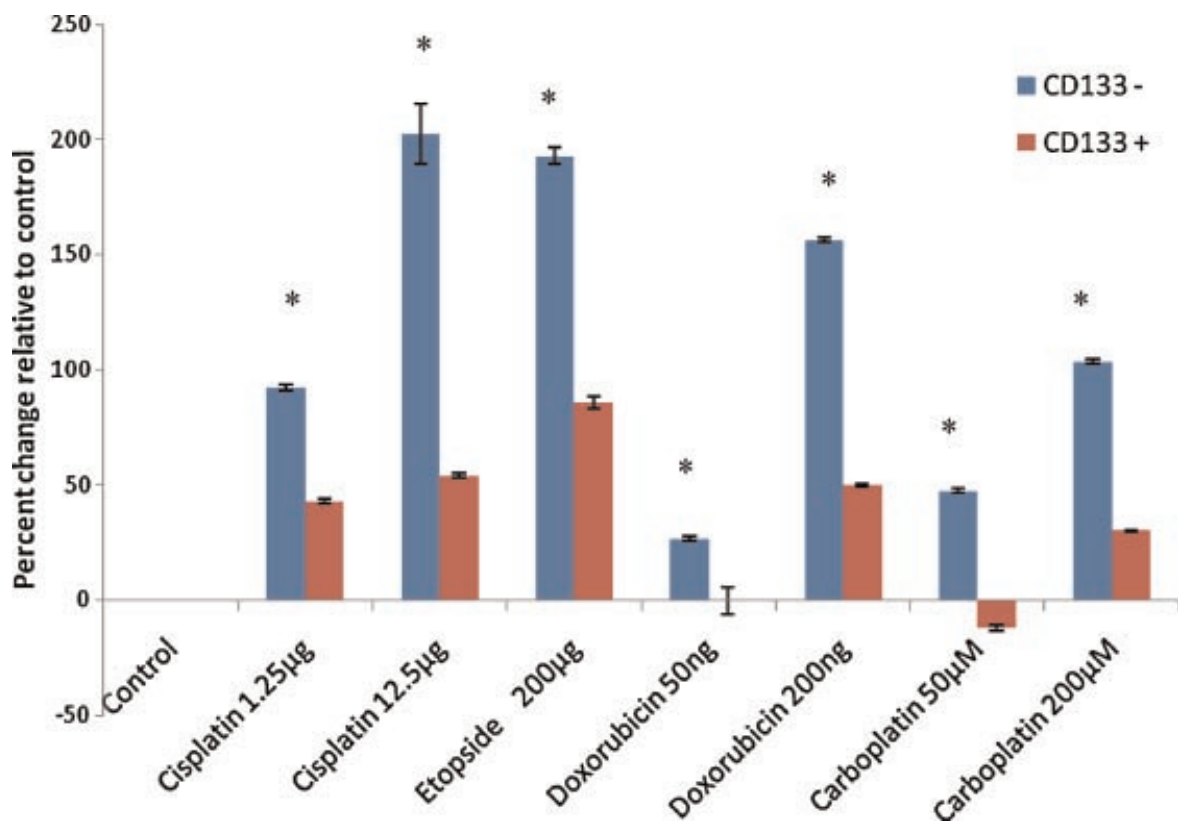

Fig. 3. Percentage of dead and apoptotic CD133+/- cells after treatment with chemotherapeutic drugs as determined by the Annexin V/PIbinding assay. Values are expressed as a percentage of dead and apoptotic cells in untreated controls and are mean $\pm \operatorname{SD}(\mathrm{n}=6$; $* P<0.005)$. [Color figure can be viewed in the online issue, which is available at www.interscience.wiley.com.]

expressing stem cell markers CD34+ and CD38-. They could generate original tumors with different phenotypes. Side population (sp) cells that export Hoechst 33342 dye have been used to identify stem-like cells in certain cancers, that generated sp and non-sp cells ex vivo [11,18].

CD133 is a stem cell marker expressed by normal neuronal stem cells [20]. Singh et al. [8] have shown that CD133+ cells isolated from human brain tumors could develop tumors in mice while CD133 - cells were not tumorigenic. Identifying stem-like cancer cells from existing cancer cell lines could lead to development of effective targeted therapies. Here we utilized the marker CD133 to identify the presence or absence of stem-like cells in various cell

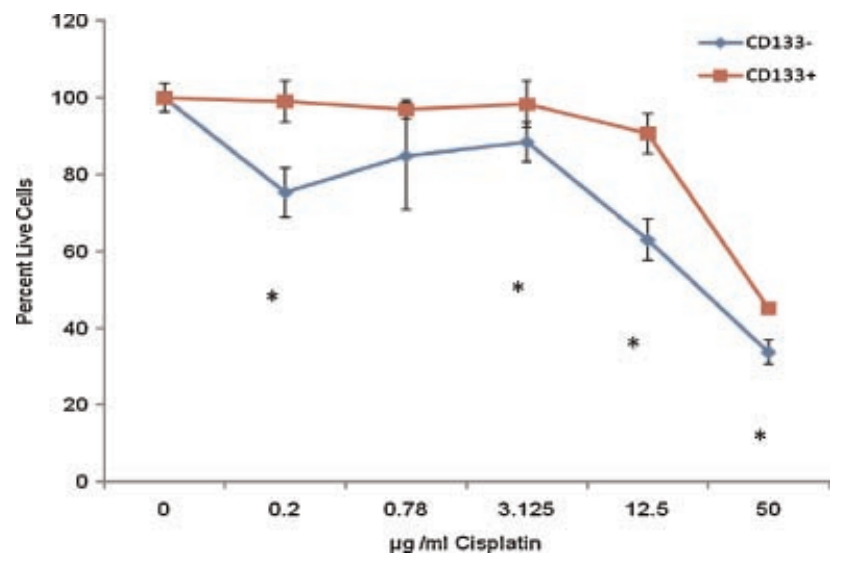

Fig. 4. Percentage of live cells in CD133+ and CD133- populations of cell line SK-N-BE after exposure to cisplatin for $24 \mathrm{hr}$ as determined by the MTT assay. Values are expressed as a percentage of untreated controls and are the mean $\pm \mathrm{SD}(\mathrm{n}=5 ; * P<0.05)$. [Color figure can be viewed in the online issue, which is available at www.interscience. wiley.com.] lines derived from human solid tumors. The tumorigenicity and differentiation potential of these CD133+ cells are yet to be determined. However, identifying differential responses of CD133 + and CD133 - cells to chemotherapeutic agents could give a better insight into the effect of anticancer medications on cancer cell lines. Ewing sarcoma cell line EWS-1 contains a very high percentage $(>85 \%) \mathrm{CD} 133+$ cells while neuroblastoma cell line SK-N-SH has $8-10 \%$ CD133+ cells. We suggest that SK-NSH cell line can serve as a model to study the differences in the cytotoxic effects of various anticancer drugs between CD133+ and CD133- cells.

\section{C131331 C1133-}

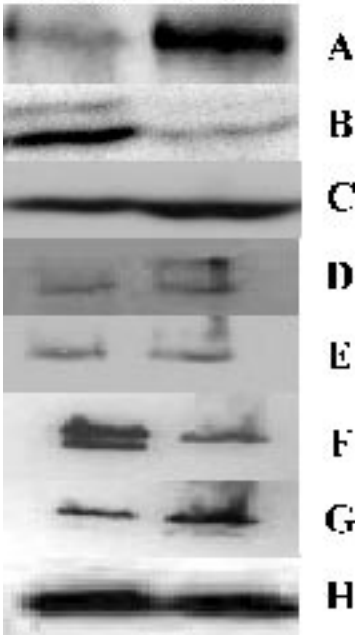

Fig. 5. Expression of kinases in CD133+ and CD133 - populations of neuroblastoma cell line SH. A: MKP-1, (B) phospho-P-38, (C) P-38, (D) phospho-JNK, (E) total JNK, (F) phospho-ERK, (G) total ERK, and (H) $\beta$-actin. The results are representative of two separate experiments. 
Several mechanisms have been proposed to explain the resistance of cancers to chemotherapeutic agents, including altered gene expression [21], hypoxia in the tumors [22], and migration of tumor cells to low drug penetration sites [23]. Keshelava et al. [24] have reported that the resistance of neuroblastoma cell lines is dependent on the patient's phase/stage of therapy when the cell lines were derived. However, in recent years, cancer stem cells have been an important focus in the study of drug resistance mechanisms [2529]. We investigated the sensitivity of CD133 + and CD133 - cells from the cell line SK-N-SH to four drugs commonly used for neuroblastoma treatment: cisplatin, etopside, doxorubicin, and carboplatin.

Keshelava et al. [24] have also shown that for cell lines derived from children with neuroblastoma both doxorubicin and carboplatin had a very high range of sensitivity compared to cisplatin and etopside. For this study we chose a wide range of drug concentrations to cover both low-dose and high-dose treatments and the concentrations correspond to the dosages used to treat patients [30-34]. MTT assay has been used as a predictor of drug sensitivity in vitro for several types of tumors [35-37]. Here we determined that CD133+ cells isolated from cell line SK-N-SH are more resistant to cisplatin, etopside, carboplatin, and doxorubicin at $72 \mathrm{hr}$. $\mathrm{CD} 133+$ cells had significantly higher percentages of live cells at all doses of the drugs tested.

Although anti-CD133-labeled magnetic microbeads have been extensively used for CD133 + cell isolation [38-43], we eliminated the possibility of the beads interfering in the observed differences by studying the effect of the chemotherapeutic drugs on CD133+ rich EWS-1 cell line, in the presence and absence of the beads. The presence of microbeads conferred no apparent change to the chemosensitivity of the cells (data available as a Supplement Online).

CD133+ cancer stem cells from glioblastomas cell lines show significant resistance to chemotherapeutic agents temozolomide, carboplatin, paclitaxel, and etopside compared to CD133-negative cells [44] similar to our observation with SK-N-SH and SK-N-BE derived CD133+ cells. Mahller et al. [12] have reported the presence of pluripotent tumor initiating cells in neuroblastoma cell lines that are CD133 and nestin positive, had increased ABCG2 expression, and were resistant to doxorubicin. Shervington and $\mathrm{Lu}$ [45] have shown that CD133-expressing glioblastoma cells coexpress multidrug resistance genes such as $m d r 1$ and $b c l-2$, and Liu et al. [44] have associated high drug resistance of CD133+ cells to expression of BCRP1 and MGMT. An in-depth gene profiling of $\mathrm{CD} 133+$ and CD133 - fractions of SK-N-SH cell line could identify the differences in gene expressions and help develop gene targeted therapies.

Mitogen-activated protein kinases (MAP kinases) play important roles in cell-cycle progression, differentiation, cell survival, and apoptosis. Three major groups comprise the family of MAP kinases: the extracellular regulated kinases (ERKs), the C-jun $\mathrm{N}$ terminal kinases (JNKs), and the p38MAP kinases [46,47]. An initial screening of the constitutive expression of kinases and phosphatase MKP-1 by Western blot analysis showed that CD133+ cells expressed higher levels of the phosphorylated forms of P-ERK and P-P38 while the expression of kinase-phosphatase MKP-1 is higher in the CD133- cells.

Four mechanisms have been proposed for the resistance of solid tumors to platinum-based drugs: (1) reduced platinum accumulation, (2) intracellular inactivation of cisplatin, (3) enhanced repair of DNA damage, and (4) blocking the induction of apoptosis and promoting cell survival [48]. Differential expression of MAP kinases (P-38, JKN, ERK, and P13K) has been implicated in the cell survival mechanism [48]. Although the traditional role of activated P-38 is in cell differentiation, growth inhibition, and apoptosis [49], Thornton and Rincon [47] have reported that $\mathrm{P}-38$ also contributes to cell survival by induction of $\mathrm{G} 2 / \mathrm{M}$ cell-cycle checkpoint in tumor and non-tumor cells. Kinases ERK1/2 have been implicated in the tumor cell survival signaling as reviewed by Balmanno and Cook [50]. Although total ERK1 (p44) is prominently expressed in both CD133+ and CD133 - populations, conspicuously low levels of ERK2 (p42) are seen in both groups. However, the phosphorylated forms of both ERK 1 and ERK2 are expressed in significantly higher levels in CD133+ cells possibly playing a role in the increased survival of CD133+ cells. JNKs are activated by various external stimuli such as environmental stresses, cytokine response, oxidant stress, and DNA damage [51]. Interestingly, we find no significant difference in the activated form of JNK between CD133+ and CD133 - cells. While the kinase cascade plays an important role in the activation of downstream kinases by phosphorylation, regulated dephosphorylation of MAPKs is crucial to determine the magnitude and duration of activation, thus determining the physiological outcome [52]. Mitogen-activated protein kinase phosphatase 1 (MKP-1) has been shown to dephosphorylate ERK, JNK, and P-38 in the cell nucleus [52]. Higher expression of MKP-1 in CD133cells relates to the increased dephosphorylation of P-38 and ERK seen in CD133 - cells. Differential activations of various MAPKs determines the cell fate by triggering downstream regulators toward apoptotic, cell survival, or differentiation pathways. Here we show that the CD133+ stem cell fraction of the SK-NSH line has constitutively higher levels of phosphorylated P-38 and ERK1/2. This could be one of the pathways by which cancer stem cells show higher resistance to chemotherapeutic drugs. A detailed study of the MAPK expression in CD133+/- cells after treatment with anticancer agents would allow us to determine the role of kinases in chemoresistance and could lead to more effective therapies.

In summary, this study shows that CD133 + cells in neuroblastoma cell lines SK-N-SH and SK-N-BE are more resistant to conventional anticancer drugs compared to CD133- cells. Differences in the activation of MAPKs and expression of MKP-1 could be partially responsible for the resistance. Further investigation is warranted to confirm the role of kinases since they may serve as molecules for targeted therapy. Similar studies are needed to be done on primary neuroblastoma tissue samples from patients to ensure the presence, and drug resistance of CD133+ cells. Targeting these CD133+ cell populations using novel agents or novel combinations of existing drugs could be one of the strategies to overcome resistance and develop more effective treatment for neuroblastoma.

\section{REFERENCES}

1. Gil J, Stembalska A, Pesz KA, et al. Cancer stem cells: The theory and perspectives in cancer therapy. J Appl Genet 2008;49:193199.

2. Besancon R, Valsesia-Wittmann S, Puisieux A, et al. Cancer stem cells: The emerging challenge of drug targeting. Curr Med Chem 2009;16:394-416. 
3. Cho RW, Clarke MF. Recent advances in cancer stem cells. Curr Opin Genet Dev 2008;18:48-53.

4. Costa FF, Le Blanc K, Brodin B. Concise review: Cancer/ testis antigens, stem cells, and cancer. Stem Cells 2007;25:707711.

5. Bonnet D, Dick JE. Human acute myeloid leukemia is organized as a hierarchy that originates from a primitive hematopoietic cell. Nat Med 1997;3:730-737.

6. Lapidot T, Sirard C, Vormoor J, et al. A cell initiating human acute myeloid leukaemia after transplantation into SCID mice. Nature 1994;367:645-648.

7. Al-Hajj M, Wicha MS, Benito-Hernandez A, et al. Prospective identification of tumorigenic breast cancer cells. Proc Natl Acad Sci USA 2003;100:3983-3988.

8. Singh SK, Hawkins C, Clarke ID, et al. Identification of human brain tumour initiating cells. Nature 2004;432:396-401.

9. Dalerba P, Dylla SJ, Park IK, et al. Phenotypic characterization of human colorectal cancer stem cells. Proc Natl Acad Sci USA 2007; 104:10158-10163.

10. Walton JD, Kattan DR, Thomas SK, et al. Characteristics of stem cells from human neuroblastoma cell lines and in tumors. Neoplasia 2004;6:838-845.

11. Hirschmann-Jax C, Foster AE, Wulf GG, et al. A distinct "side population" of cells in human tumor cells: Implications for tumor biology and therapy. Cell Cycle 2005;4:203-205.

12. Mahller YY, Williams JP, Baird WH, et al. Neuroblastoma cell lines contain pluripotent tumor initiating cells that are susceptible to a targeted oncolytic virus. PLoS ONE 2009;4:e4235.

13. Beier D, Hau P, Proescholdt M, et al. CD133(+) and CD133(-) glioblastoma-derived cancer stem cells show differential growth characteristics and molecular profiles. Cancer Res 2007;67:40104015.

14. Bernstein ML, Leclerc JM, Bunin G, et al. A population-based study of neuroblastoma incidence, survival, and mortality in North America. J Clin Oncol 1992;10:323-329.

15. Barami K, Grever WE, Diaz FG, et al. An efficient method for the culturing and generation of neurons and astrocytes from second trimester human central nervous system tissue. Neurol Res 2001;23:321-326.

16. Wang Z, Xu J, Zhou JY, et al. Mitogen-activated protein kinase phosphatase- 1 is required for cisplatin resistance. Cancer Res 2006;66:8870-8877.

17. Ozgen U, Savasan S, Buck S, et al. Comparison of DiOC(6)(3) uptake and annexin $\mathrm{V}$ labeling for quantification of apoptosis in leukemia cells and non-malignant $\mathrm{T}$ lymphocytes from children. Cytometry 2000;42:74-78.

18. Komuro H, Saihara R, Shinya M, et al. Identification of side population cells (stem-like cell population) in pediatric solid tumor cell lines. J Pediatr Surg 2007;42:2040-2045.

19. Hirschmann-Jax C, Foster AE, Wulf GG, et al. A distinct "side population" of cells with high drug efflux capacity in human tumor cells. Proc Natl Acad Sci USA 2004;101:14228-14233.

20. Uchida N, Buck DW, He D, et al. Direct isolation of human central nervous system stem cells. Proc Natl Acad Sci USA 2000;97: $14720-14725$.

21. LaQuaglia MP, Kopp EB, Spengler BA, et al. Multidrug resistance in human neuroblastoma cells. J Pediatr Surg 1991;26:11071112 .

22. Kennedy KA. Hypoxic cells as specific drug targets for chemotherapy. Anticancer Drug Des 1987;2:181-194.

23. Kushner BH, Vogel R, Hajdu SI, et al. Metastatic neuroblastoma and testicular involvement. Cancer 1985;56:1730-1732.

24. Keshelava N, Seeger RC, Groshen S, et al. Drug resistance patterns of human neuroblastoma cell lines derived from patients at different phases of therapy. Cancer Res 1998;58:5396-5405.
25. Todaro M, D'Asaro M, Caccamo N, et al. Efficient killing of human colon cancer stem cells by gammadelta T lymphocytes. J Immunol 2009; 182:7287-7296.

26. Shervington A, Lu C, Patel R, et al. Telomerase downregulation in cancer brain stem cell. Mol Cell Biochem 2009.

27. Nakai E, Park K, Yawata T, et al. Enhanced MDR1 expression and chemoresistance of cancer stem cells derived from glioblastoma. Cancer Investigation 2009;27:901-908.

28. Mathew M, Verma RS. Humanized immunotoxins: A new generation of immunotoxins for targeted cancer therapy. Cancer Sci 2009;100:1359-1365.

29. Johannessen TC, Wang J, Skaftnesmo KO, et al. Highly infiltrative brain tumours show reduced chemosensitivity associated with a stem cell-like phenotype. Neuropathol Applied Neurobiol 2008;35:380393.

30. Robson H, Meyer S, Shalet SM, et al. Platinum agents in the treatment of osteosarcoma: Efficacy of cisplatin vs. carboplatin in human osteosarcoma cell lines. Med Pediatr Oncol 2002;39:573-580.

31. Ritzmo C, Soderhall S, Karlen J, et al. Pharmacokinetics of doxorubicin and etoposide in a morbidly obese pediatric patient. Pediatr Hematol Oncol 2007;24:437-445

32. Pein F, Pinkerton R, Berthaud P, et al. Dose finding study of oral PSC 833 combined with weekly intravenous etoposide in children with relapsed or refractory solid tumours. Eur J Cancer 2007; 43:2074-2081.

33. Ekhart C, de Jonge ME, Huitema AD, et al. Flat dosing of carboplatin is justified in adult patients with normal renal function. Clin Cancer Res 2006;12:6502-6508.

34. Busse D, Wurthwein G, Hinske C, et al. Pharmacokinetics of intravenous etoposide in patients with breast cancer: Influence of dose escalation and cyclophosphamide and doxorubicin coadministration. Naunyn Schmiedebergs Arch Pharmacol 2002;366: $218-225$.

35. Sargent JM. The use of the MTT assay to study drug resistance in fresh tumour samples. Recent Results Cancer Res 2003;161:13-25.

36. Hayon T, Dvilansky A, Shpilberg O, et al. Appraisal of the MTTbased assay as a useful tool for predicting drug chemosensitivity in leukemia. Leuk Lymphoma 2003;44:1957-1962.

37. Kratzke RA, Kramer BS. Evaluation of in vitro chemosensitivity using human lung cancer cell lines. J Cell Biochem Suppl 1996;24:160-164.

38. Martinez HR, Gonzalez-Garza MT, Moreno-Cuevas JE, et al. Stem-cell transplantation into the frontal motor cortex in amyotrophic lateral sclerosis patients. Cytotherapy 2009;11:26-34.

39. Clement V, Dutoit V, Marino D, et al. Limits of CD133 as a marker of glioma self-renewing cells. Int J Cancer 2009;125:244-248.

40. Liu J, Chao B. MRI-based visualization of iron-labeled CD133+ human endothelial progenitor cells. Biol Trace Elem Res 2008; 126:83-91.

41. Drewa T, Wolski Z, Pokrywka L, et al. Progenitor cells are responsible for formation of human prostate epithelium primary cultures. Exp Oncol 2008;30:148-152.

42. Jaatinen T, Laine J. Isolation of hematopoietic stem cells from human cord blood. Curr Protoc Stem Cell Biol 2007; Chapter 2: Unit 2A.2.

43. Drewa T, Styczynski J. Progenitor cells are responsible for formation primary epithelial cultures in the prostate epithelial model. Int Urol Nephrol 2007;39:851-857.

44. Liu G, Yuan X, Zeng Z, et al. Analysis of gene expression and chemoresistance of CD133+ cancer stem cells in glioblastoma. Mol Cancer 2006;5:67.

45. Shervington A, Lu C. Expression of multidrug resistance genes in normal and cancer stem cells. Cancer Invest 2008;26:535-542.

46. Raman M, Chen W, Cobb MH. Differential regulation and properties of MAPKs. Oncogene 2007;26:3100-3112. 
47. Thornton TM, Rincon M. Non-classical p38 map kinase functions: Cell cycle checkpoints and survival. Int J Biol Sci 2009;5: $44-51$.

48. Ohmichi M, Hayakawa J, Tasaka K, et al. Mechanisms of platinum drug resistance. Trends Pharmacol Sci 2005;26:113-116.

49. Hui L, Bakiri L, Stepniak E, et al. p38alpha: A suppressor of cell proliferation and tumorigenesis. Cell Cycle 2007;6:24292433.
50. Balmanno K, Cook SJ. Tumour cell survival signalling by the ERK1/2 pathway. Cell Death Differ 2009;16:368-377.

51. Kyriakis JM, Avruch J. Mammalian mitogen-activated protein kinase signal transduction pathways activated by stress and inflammation. Physiol Rev 2001;81:807-869.

52. Owens DM, Keyse SM. Differential regulation of MAP kinase signalling by dual-specificity protein phosphatases. Oncogene 2007;26:3203-3213. 